\title{
Analisis Text Mining dari Cuitan Twitter Mengenai Infrastruktur di Indonesia dengan Metode Klasifikasi Nä̈ve Bayes
}

\author{
Bimananda $W^{a}$, Insan Riski, ${ }^{a,}$, Karina Dwi ${ }^{a}$, Rani Nooraeni ${ }^{a}$ Theresa Siahaan ${ }^{a}$, Yosherina \\ Dhea $^{a}$ \\ ${ }^{\text {a }}$ Politeknik Statistika STIS \\ *Email: insanriski@gmail.com
}

\begin{abstract}
A B S T R A C T
Development aims to improve the welfare of the community. During the administration of President Joko Widodo, the development of infrastructure was very intensively carried out to support economic growth and increase people's welfare. This infrastructure development has certainly had a lot of impacts on community activities, both positive and negative. Regardless of the impact produced, people often provide opinions or comments related to infrastructure development. The public expressed their aspirations for infrastructure development and the impact they felt through various social media networks, one of which was Twitter. The results show that the proportion of negative sentiment is greater than the positive sentiment. In addition, the results of the classification using the Naïve Bayes method obtained the best model in the airport model with an accuracy of $82 \%$, a precision of 0.84 and a recall of 0.48 .
\end{abstract}

Keywords : infrastructure, Nä̈ve Bayes, accuracy, precision, recall

\section{A B S T R A K}

Pembangunan bertujuan untuk meningkatkan kesejahteraan masyarakat. Pada masa pemerintahan Presiden Joko Widodo sangat gencar dilakukan pembangunan infrastruktur untuk mendukung pertumbuhan ekonomi dan peningkatan kesejahteraan masyarakat. Pembangunan infrastruktur ini tentu telah banyak memberikan dampak pada aktivitas masyarakat baik dari sisi positif maupun negatif. Terlepas dari dampak yang dihasilkan, masyarakat kerap kali memberikan pendapat atau komentar terkait dengan pembangunan infrastruktur. Masyarakat menyampaikan aspirasinya terhadap pembangunan infrastruktur dan dampak apa yang dirasakannya melalui berbagai jejaring media sosial salah satunya adalah Twitter. Diperoleh hasil bahwa proporsi sentimen negatif lebih besar dibandingkan dengan sentimen positif. Selain itu, hasil pengklasifikasian dengan menggunakan metode Naïve Bayes diperoleh model yang paling baik pada model bandara dengan akurasi sebesar $82 \%$, presisi sebesar 0,84 dan recall sebesar 0,48 .

* Corresponding Author

Alamat e-mail: karinadwi11897@gmail.com 
Keywords: infrastruktur, Naïve Bayes, akurasi, presisi, recall

Diserahkan: 09-11-2019; Diterima: 31-12-2019;

Doi: https://doi.org/10.29303/emj.v1i2.36

\section{Pendahuluan}

Pembangunan di suatu negara bertujuan untuk meningkatkan kesejahteraan masyarakat. Peran pemerintah sebagai pelaku utama pembangunan sangat berperan dalam peningkatan kesejahteraan. Pada masa pemerintahan Presiden Joko Widodo sangat gencar dilakukan pembangunan infrastruktur untuk mendukung pertumbuhan ekonomi dan peningkatan kesejahteraan masyarakat. Infrastruktur dipandang sebagai roda yang menggerakkan pertumbuhan perekonomian karena berpengaruh penting untuk peningkatan kualitas hidup dan kesejahteraan masyarakat. Di era pemerintahan Indonesia kali ini, program kerja pemerintah difokuskan pada pembangunan infrastruktur. Hal ini dikarenakan stok infrastruktur Indonesia memang masih sangat rendah dan kalah jauh dibandingkan negara-negara tetangga. Pembangunan infrastruktur ini tentu telah banyak memberikan dampak pada aktivitas masyarakat, baik dari sisi positif maupun negatif.

Dalam melakukan pembangunan, pemerintah membuat kebijakan untuk meringankan beban usaha. Salah satu prioritas yang dibuat adalah peningkatan pembangunan proyek infrastruktur di seluruh Indonesia untuk mengatasi gelombang pengangguran. Pembangunan infrastruktur yang dapat menyerap banyak tenaga kerja antara lain pembangunan jalan, jembatan, pelabuhan, dermaga, energi, perhubungan, dan perumahan. Selain menyerap banyak tenaga kerja, pembangunan infrastruktur juga dapat menggerakkan perekonomian yang tentunya membawa dampak pada kesejahteraan masyarakat.

Namun, pembangunan infrastruktur yang gencar tentunya memerlukan biaya yang tidak sedikit. Padahal jika dilihat dari sisi hutang negara, Indonesia terus mengalami pembengkakan. Banyak ahli yang menyatakan bahwa hutang Indonesia saat ini sangat mengkhawatirkan. Selain dari sisi hutang, pembangunan infrastruktur juga berdampak pada lingkungan. Penggunaan lahan secara besar- besaran dapat mengakibatkan kerusakan lingkungan, terkikisnya sumber daya alam, dan adanya pengalihan fungsi lahan.

Terlepas dari dampak yang dihasilkan, masyarakat kerap kali memberikan pendapat atau komentar terkait dengan pembangunan infrastruktur. Pendapat tersebut kerap kali disampaikan melalui berbagai jejaring media sosial yang telah berkembang saat ini, salah satunya adalah Twitter. Pada twitter masyarakat dapat memberikan komentar apapun baik secara positif maupun negatif. Oleh sebab itu, cuitan komentar masyarakat pada Twitter merupakan informasi yang penting untuk dianalisis agar pemerintah mengetahui bagaimana sebenarnya respon masyarakat terhadap infrastruktur di Indonesia dan mampu menentukan kebijakankebijakan selanjutnya yang bisa diambil guna untuk meningkatkan kesejahteraan rakyat. Sehingga pada penelitian ini dilakukan analisis sentimen dengan metode klasifikasi Nä̈ve Bayes.

\section{Kajian Pustaka}

\subsection{Infrastruktur}

Menurut N. Gregory Mankiw (2003), arti infrastruktur dalam ilmu ekonomi adalah wujud dari public capital (modal kapital) yang dibentuk dari investasi pemerintah, seperti MRT, tol, dan bandara. Sedangkan menurut Neil S. Grigg (1998), infrastruktur adalah sistem fisik yang menyediakan sarana transportasi, drainase, pengairan, bangunan gedung, dan fasilitas publik lainnya yang dibutuhkan untuk memenuhi berbagai macam kebutuhan dasar manusia, baik itu kebutuhan sosial maupun kebutuhan ekonomi. Robert J. Kodoatie (2005) berpendapat bahwa infrastruktur adalah suatu sistem yang menunjang sistem sosial dan ekonomi yang secara sekaligus menjadi penghubung sistem lingkungan, dimana sistem ini bisa digunakan sebagai dasar dalam mengambil kebijakan. Jadi, infrastruktur adalah segala wujud fasilitas publik yang dibangun pemerintah untuk 
memenuhi kebutuhan dasar manusia seperti menyediakan sarana transportasi, drainase, pengairan, bangunan gedung, dan berbagai fasilitas publik lainnya.

Pada saat ini pembangunan infrastruktur sangat gencar dilakukan. Berbagai pembangunan telah dilakukan oleh pemerintah agar memudahkan segala bentuk kegiatan masyarakat. Adapun berbagai bentuk pembangunan yang telah dilakukan seperti dibangunnya MRT, bandara, jalan tol, bendungan, dll. Hal ini tentu akan memberikan dampak pada aktivitas masyarakat baik secara positif maupun negatif. Pentingnya infrastruktur untuk dikembangkan agar kegiatan masyarakat, baik kegiatan sosial maupun ekonomi dapat berjalan dengan baik dan lebih efisien.

\subsection{Twitter}

Di era yang serba cepat ini, setiap orang menuntut dengan cepat untuk mendapatkan berbagai informasi yang akurat dan tentunya tetap terhubung dengan banyak orang. Penggunaan media sosial bukan lagi suatu hal yang asing untuk masyarakat sekarang ini. Kemudahan akses dan banyaknya informasi yang beredar menjadi daya tarik bagi pengguna media sosial. Pengguna media sosial secara bebas menggunakan setiap media sosial yang ada, tidak ada batasan waktu, tempat, bahkan jenis informasi.

Twitter adalah salah satu situs microblogging yang mana memungkinkan penggunanya untuk menulis tentang berbagai topik dan membahas isu-isu yang terjadi pada saat ini (Manalu,2014). Penggunanya menyampaikan pemikirannya itu melalui pesan pendek dengan batasan 140 karakter yang disebut dengan Tweet atau cuitan. Dengan adanya Twitter, para pengguna bisa dengan bebas menyampaikan pendapatnya, bertukar pikiran dengan pengguna lainnya, dan dengan mudah mendapatkan informasi, tren, dan berita yang sedang terjadi di seluruh dunia. Twitter ini juga bisa menjadi salah satu media sosial untuk bisa berkomunikasi dengan orang- orang yang dikenal maupun yang tidak dikenal. Selain itu, jejaring sosial twitter juga seringkali digunakan sebagai tempat menyampaikan tanggapan atau pendapat mengenai sesuatu hal berupa cuitan atau tweet yang dapat berupa tanggapan secara positif maupun negatif. Twitter menjadi wadah bagi para penggunanya untuk menyalurkan apa yang mereka rasakan, alami, dan juga bisa memberikan respon terhadap apa yang dunia sedang alami melalui suatu fenomena ataupun kejadian yang sedang terjadi.

\subsection{Analisis Sentimen}

Seiring berkembangnya jejaring sosial di masyarakat, banyak diantaranya yang mengekspresikan segala bentuk perasaan, tanggapan, reaksi terhadap sesuatu melalui status yang dipasang di jejaring sosial salah satunya adalah tweet pada Twitter. Dengan banyaknya tanggapan yang diberikan oleh pengguna Twitter terhadap suatu isu baik secara positif atau negatif, hal ini tentu bisa dilakukan analisis mengenai bagaimana tanggapan masyarakat terhadap suatu hal dengan melakukan analisis sentimen. Sentiment analysis atau analisis sentimen dalam Bahasa Indonesia adalah sebuah teknik atau cara yang digunakan untuk mengidentifikasi bagaimana sebuah sentimen diekspresikan menggunakan teks dan bagaimana sentimen tersebut bisa dikategorikan sebagai sentimen positif maupun sentimen negatif (Nasukawa \& Yi, 2003). Dengan kata lain analisis sentimen adalah sebuah proses untuk menentukan sentimen atau opini dari seseorang yang diwujudkan dalam bentuk teks dan bisa dikategorikan sebagai sentimen positif atau negatif.

\subsection{Nä̈ve Bayes}

Naïve Bayes merupakan metode klasifikasi berbasis probabilita/peluang, dimana dihitung sekumpulan probabilitas dengan menjumlahkan frekuensi dan kombinasi nilai dari dataset yang diberikan (Pramana, Yuniarto, Mariyah, Santoso, \& Nooraeni, 
2018). Pada metode ini menggunakan Teorema Bayes dan mengasumsikan semua atribut independen. Adapun Teorema Bayes adalah sebagai berikut :

$P(H \mid X)=\frac{P(X \mid H) \cdot P(H)}{P(X)}$

dimana :

$X \quad$ : Data dengan kelas yang belum diketahui

$H \quad$ : Hipotesis data merupakan suatu kelas spesifik

$P(H \mid X):$ Probabilitas hipotesis $\mathrm{H}$ berdasar kondisi X (probabilitas posterior)

$P(H)$ : Probabilitas hipotesis $\mathrm{H}$ (probabilitas prior)

$P(X \mid H)$ : Probabilitas $\mathrm{X}$ berdasarkan kondisi pada hipotesis $\mathrm{H}$

$P(X) \quad$ : Probabilitas

\section{Metode Penelitian}

\subsection{Sumber dan Cakupan Data}

Data yang digunakan bersumber dari data Twitter berupa tweet berbahasa Indonesia yang di-post di seluruh wilayah Indonesia. Beberapa kata kunci yang digunakan sebagai variabel penelitian antara lain adalah MRT, bandara, dan jalan tol. Adapun untuk variabel MRT, data diambil pada rentang waktu 1-7 April 2019. Sedangkan untuk bandara dan jalan tol pengambilan data dilakukan pada rentang 3-9 Juni 2019.

\subsection{Tahapan Metode}

Adapun tahapan dalam penelitian ini adalah:

1. Studi Literatur

Langkah pertama dalam penelitian ini yaitu studi literatur dengan membaca jurnal penelitian orang lain yang relevan sebagai referensi.

2. Pengumpulan Data

Dalam penelitian ini, data diambil dari Twitter. Pengambilan data dari Twitter cukup mudah dilakukan karena Twitter menyediakan API. Pengambilan data twitter dilakukan dengan metode crawling data menggunakan software Phyton.

3. Pelabelan Data
Pelabelan data bertujuan membagi data menjadi beberapa kelas sentimen. Dalam penelitian ini, kelas sentimen dibagi menjadi dua, yaitu sentimen positif dan negatif. Pembagian label menjadi positif dan negative menggunakan kamus sentimen yang telah diberi bobot dengan kekuatan sentimen 1 sampai 5 dan -1 sampai -5 dimana nilai 5 sentimen positif paling kuat dan -5 sentimen negatif paling kuat. Kamus sentimen yang digunakan dalam penelitian ini didapatkan dari Wahid dan Azhari (2016) dalam penelitiannya yang berjudul Peringkasan Sentimen Ekstraktif di Twitter Menggunakan Hybrid TF-IDF dan Cosine Similarity. Proses pelabelan ini, dataset dibagi menjadi dua bagian, yaitu training data dan testing data. Training data adalah data yang digunakan untuk melatih sistem agar dapat mengenali pola yang dicari, sedangkan testing data adalah data yang digunakan untuk menguji hasil pelatihan yang sudah dilakukan.

4. Praproses Data

Dalam tahapan ini, data disiapkan agar siap untuk dianalisis.

a. Tokenization

Tokenisasi adalah sebuah proses memotong atau memecah kalimat menjadi beberapa bagian atau kata. Hasil pemotongan ini disebut token.

b. Cleansing

Cleansing dilakukan untuk membuang karakter dan tanda baca yang tidak diperlukan, seperti titik, koma, tanda seru, dan tanda tanya.

c. Filtering

Filtering bertujuan untuk menghilangkan kata-kata yang sering muncul, namun tidak memiliki makna yang berarti (stop words). Penghapusan stop words perlu dilakukan agar 
peneliti dapat fokus pada katakata lain yang lebih penting.

5. Proses Klasifikasi

Salah satu metode klasifikasi adalah Nä̈ve Bayes. Nä̈ve Bayes adalah sebuah metode pengelompokkan yang digunakan untuk memprediksi probabilitas suatu class. Metode ini mempunyai akurasi dan kecepatan yang sangat kuat bila diterapkan pada big data. Naïve Bayes mengasumsikan keberadaan maupun tidak keberadaan sebuah fitur dalam sebuah kelas tidak memiliki keterkaitan dengan keberadaan maupun tidak keberadaan fitur lainnya.

6. Visualisasi

Visualisasi yang digunakan adalah Wordcloud. Wordcloud menampilkan katakata yang menjelaskan setiap kelompok klasifikasi.

\subsection{Algoritma}

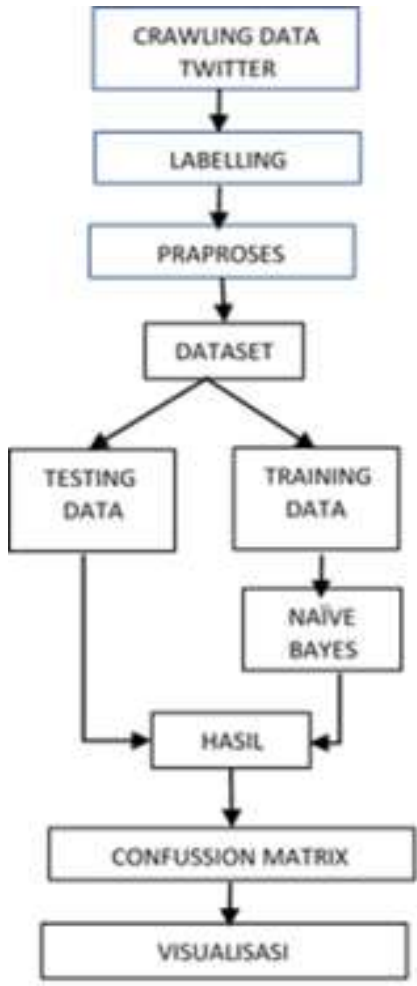

Gambar 1. Algoritma analisis sentimen

\section{Hasil dan Pembahasan}

Data yang digunakan pada penelitian ini bersumber dari Twitter yang diambil dengan metode crawling. Adapun yang dijadikan sebagai variabel untuk menggambarkan infrastruktur Indonesia saat ini adalah MRT, bandara, dan jalan tol. Pada variabel MRT data diambil pada rentang 1-7 April 2019 dan diperoleh 4551 tweet. Sedangkan untuk variabel jalan tol dan bandara diambil pada rentang 3-9 Juni 2019 dan diperoleh data masing-masing 6436 tweet dan 5764 tweet. Dari dataset tersebut kemudian dilabelkan menjadi sentimen postif dan sentimen negatif, sedangkan sentimen netral tidak digunakan pada penelitian ini. Adapun hasil sentimen pada setiap variabel adalah sebagai berikut :

Tabel 1. Hasil pelabelan sentimen

\begin{tabular}{lcc}
\hline Infrastruktur & $\begin{array}{c}\text { Sentimen } \\
\text { positif }\end{array}$ & $\begin{array}{c}\text { Sentimen } \\
\text { negatif }\end{array}$ \\
\hline Bandara & 960 & 2050 \\
\hline Jalan tol & 425 & 4814 \\
\hline MRT & 766 & 1393 \\
\hline
\end{tabular}

Berdasarkan hasil diatas dapat diketahui bahwa masyarakat cenderung lebih sering memberikan sentimen/ komentar negatif terhadap infrastruktur di Indonesia. Jika kita melihat secara persentase pada semua variabel sentiment negatif memiliki presentase lebih dari $50 \%$ dibandingkan sentiment positif. Hal ini tentu bisa dijadikan dasar dalam permbaikan dan pembangunan infrastruktur oleh pemerintah sehingga dapat terciptanya kesejahteraan masyarakat.

Selanjutnya dataset tersebut dibagi menjadi dua yaitu data training dan data testing dengan rasio pembagian 75 dan 25 . Sehingga untuk data training yang digunakan sebesar 1500 tweet dan data testing sebesar 500 tweet untuk masing-masing variabel. Setelah dibagi menjadi data training dan data testing kemudian dilakukan praposesing dan pengklasifikasian yang dimana pada penelitian ini digunakan metode Nä̈ve Bayes. Dari data testing pada masing-masing variabel diperoleh confussion matrix dengan akurasi sebagai berikut : 
Tabel 2. Confussion matrix dan akurasi

\begin{tabular}{ccccc}
\hline \multirow{2}{*}{$\begin{array}{c}\text { Infrastruk- } \\
\text { tur }\end{array}$} & $\begin{array}{c}\text { Aktual } \\
\text { Prediksi }\end{array}$ & Neg & Pos & $\begin{array}{c}\text { Aku- } \\
\text { rasi }\end{array}$ \\
\hline Bandara & Neg & 339 & 76 & $82 \%$ \\
\cline { 2 - 4 } & Pos & 14 & 71 & \\
\hline Jalan tol & Neg & 335 & 121 & \multirow{2}{*}{$75 \%$} \\
\cline { 2 - 4 } & Pos & 3 & 41 & \\
\hline MRT & Neg & 292 & 74 & \multirow{2}{*}{$80 \%$} \\
\cline { 2 - 4 } & Pos & 28 & 106 & \\
\hline
\end{tabular}

Keterangan :

Pos : sentimen positif

Neg : sentimen negatif

Berdasarkan hasil metode pengklasifikasian dengan Naïve Bayes pada tabel 2, diperoleh model yang terbentuk cukup baik dengan nilai akurasi yang lebih dari $70 \%$. Adapun variabel dengan akurasi tertinggi adalah variabel bandara dengan akurasi sebesar $82 \%$, kemudian MRT sebesar $80 \%$ dan jalan tol sebesar $75 \%$. Selain dengan akurasi, untuk melihat kebaikan suatu model dapat dilihat juga dari presisi dan recall. Berikut adalah hasil perhitungan presisi dan recall pada ketiga variabel infrastruktur tersebut.

Tabel 3. Tingkat presisi dan recall

\begin{tabular}{lcc} 
Infrastruktur & Presisi & Recall \\
\hline Bandara & 0.84 & 0.48 \\
\hline Jalan tol & 0.93 & 0.25 \\
\hline MRT & 0.79 & 0.59 \\
\hline
\end{tabular}

Berdasarkan tabel 3 diatas diperoleh bahwa variabel dengan presisi terbaik adalah jalan tol dengan presisi sebesar 0,93 dan untuk validasi recall tertiinggi diperoleh oleh variabel MRT. Jika dilihat dari hasil validitas keseluruhan metode Nä̈ve Bayes sudah cukup baik dalam mengklasifikasikan sentimen negatif maupun positif. Dari ketiga hasil tersebut diperoleh bahwa variabel bandara merupakan model yang terbaik dengan akurasi, presisi, dan recall yang cukup baik dibandingkan variabel yang lain.

Selanjutnya dilakukan visualisasi dengan menggunakan Wordcloud untuk masing-masing variabel. Adapun untuk Wordcloud dari masingmasing variabel adalah sebagai berikut:

a. Bandara

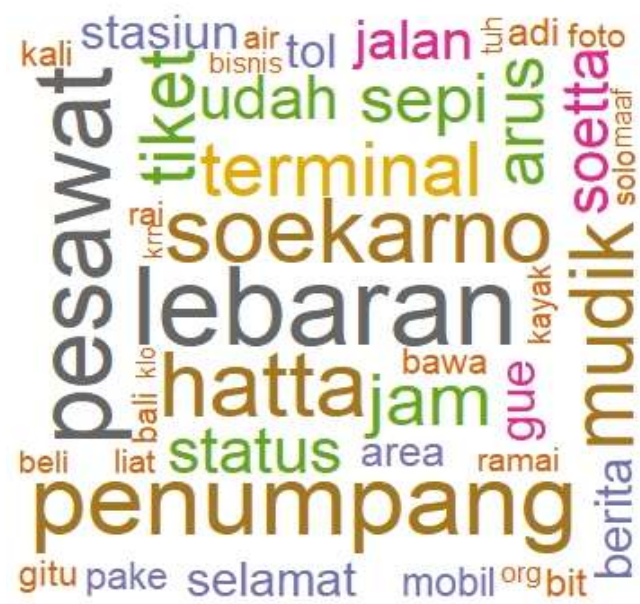

Gambar 1. World Cloud Bandara

Berdasarkan gambar tersebut dapat dilihat bahwa dari wordcloud tersebut menampilkan bahwa kata "Lebaran dan Pesawat" terlihat memiliki ukuran paling besar dibandingkan dengan kata yang lainnya artinya kata Lebaran dan Pesawat menjadi kata yang paling sering muncul di tweet terkait dengan infrastruktur. Kemudian kata lain yang memiliki frekuensi yang tinggi berikutnya yaitu "penumpang, Soekarno Hatta, mudik". Kata-kata ini terlihat jelas pada tampilan wordcloud tersebut yang menunjukkan bahwa kata tersebut berkaitan dengan Bandara. Bandara adalah terminal untuk pesawat dan kata lebaran juga terlihat jelas pada tampilan wordcloud karena tweet diambil pada rentang hari lebaran dan menunjukkan banyaknya penumpang yang mudik serta mayoritas melalui bandara Soekarno Hatta.

Berdasarkan Wordcloud bandara, kata-kata yang menunjukkan respon negatif adalah "sepi, tiket". Hal ini menunjukkan bandara menjadi lebih sepi karena pada rentang waktu pengumpulan data, harga tiket lebih mahal. 
b. Jalan Tol

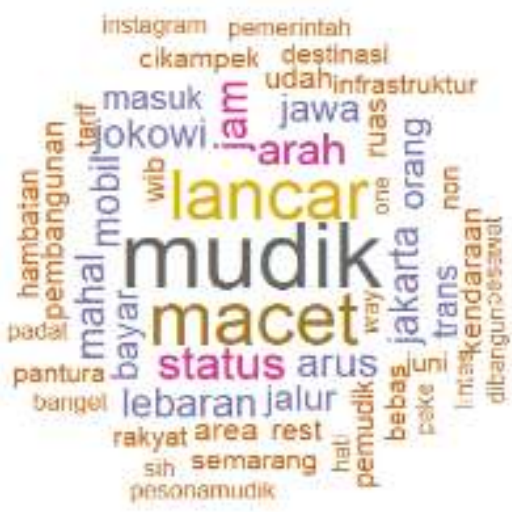

Gambar 2. World Cloud Jalan Tol

Berdasarkan gambar tersebut dapat dilihat bahwa dari wordcloud tersebut menampilkan bahwa kata mudik terlihat memiliki ukuran paling besar dibandingkan dengan kata yang lainnya artinya kata "mudik" menjadi kata yang paling sering muncul di tweet terkait dengan infrastruktur. Kemudian kata lain yang memiliki frekuensi yang tinggi berikutnya yaitu "macet dan lancar". Kata-kata tersebut terlihat jelas pada tampilan wordcloud tersebut yang menunjukkan bahwa berkaitan dengan Jalan Tol karena pada saat mudik pengendara melewati jalan tol dan selama itu arus mudik terpantau lancar dan ada juga di beberapa titik yang macet.

Berdasarkan Wordcloud jalan tol, kata-kata yang menunjukkan respon negatif adalah "macet, mahal". Hal ini menunjukkan saat rentang waktu pengumpulan data, kondisi jalan tol macet dan tarif jalan tol lebih mahal.

\section{c. MRT}

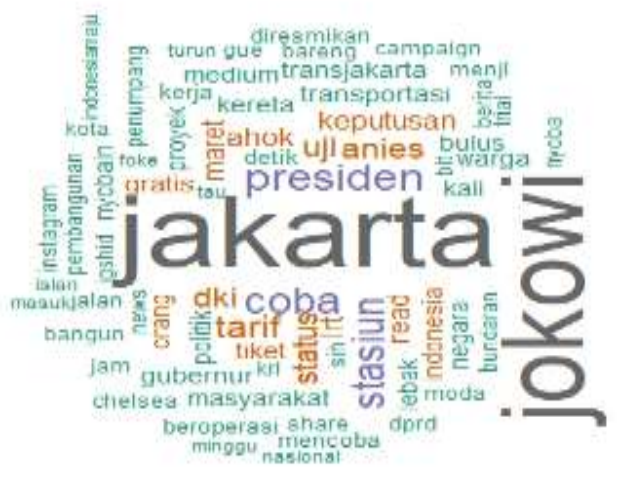

Gambar 3. World Cloud MRT
Berdasarkan gambar tersebut dapat dilihat bahwa dari wordcloud tersebut menampilkan bahwa kata Jakarta dan Jokowi terlihat memiliki ukuran paling besar dibandingkan dengan kata yang lainnya artinya kedua kata ini menjadi kata yang paling sering muncul di tweet terkait dengan pembangunan infrastruktur. Kemudian terdapat kata lain yang memiliki frekuensi yang tinggi berikutnya yaitu "coba, stasiun". Kata Jakarta dan Jokowi terlihat jelas pada tampilan wordcloud tersebut yang menunjukkan bahwa kata tersebut berkaitan dengan MRT karena lokasi dari MRT tersebut ada di Jakarta dan diresmikan di era pemerintahan Presiden Jokowi. Kata "coba" juga terlihat jelas pada tampilan wordcloud yang menunjukkan bahwa adanya antusiasme dari masyarakat terhadap peresmian MRT dan keinginan masyarakat untuk mencoba transportasi baru tersebut.

\section{Kesimpulan dan Saran 5.1. Kesimpulan}

Berdasarkan hasil pengujian yang telah dilakukan, ada beberapa kesimpulan yang diperoleh. Kesimpulan tersebut antara lain :

a. Respon masyarakat terhadap pembangunan infrastruktur di Indonesia berdasarkan analisis sentimen yang dilakukan menunjukkan hasil yang negatif. Hal ini menunjukkan bahwa masyarakat belum merasa puas dengan pembangunan infrastruktur yang ada.

b. Berdasarkan hasil pengklasifikasian dengan menggunakan Naive Bayesian diperoleh hasil akurasi, presisi, dan recall yang cukup baik untuk semua variabel yang digunakan untuk menggambarkan pembangunan infrastruktur, terutama pada variabel bandara karena memiliki akurasi yang tertinggi, presisi, dan recall yang cukup baik.

\subsection{Saran}

Adapun beberapa saran yang dapat diajukan adalah:

a. Dengan respon yang negatif dari masyarakat, maka pemerintah dapat melanjutkan rencana pembangunan infrastruktur dengan meningkatkan 
pelayanan dan kualitas dari pembangunan infrastruktur tersebut.

b. Bagi peneliti dapat melakukan penelitian lebih lanjut mengenai metode klasifikasi pada analisis sentimen untuk diperoleh model terbaik.

\section{DAFTAR PUSTAKA}

Faradillah Nuke dkk. (2016). Eksperimen Sistem Klasifikasi Analisa Sentimen Twitter Pada Akun Resmi Pemerintah Kota Surabaya Berbasis Pembelajaran Mesin. Seminar Nasional Sistem Informasi Indonesia

Grigg, N. Dan Fontane, D. G. 2000, Infrastructure System Management \& Optimazation Internasional Civil Engineering Departement Diponegoro University

Mankiw, N. Gregory (2003). Teori Makroekonomi Edisi Kelima. Terjemahan. Jakarta: Penerbit Erlangga.

Nasukawa, T. and Yi, J. (2003) Sentiment Analysis: Capturing Favorability Using Natural Language Processing. Proceedings of the 2nd International Conference on Knowledge Capture, Florida, 2325 October 2003, 70-77

Niasita, A. F., Adikara, P. P., \& Adinugroho, S. (2019). Analisis Sentimen Pembangunan Infrastruktur di Indonesia dengan Automatic Lexicon Word2Vec dan Naive Bayes. Jurnal Pengembangan Teknologi dan Informasi, 26732679.

pengertian-infrastruktur. (n.d.). Retrieved from https://materibelajar.co.id.

Pramana, S., Yuniarto, B., Mariyah, S., Santoso, I., \& Nooraeni, R. (2018). Data Mining dengan R. Bogor: Inmedia.

Wahid, D. H., \& Azhari, S. N. (2016). Peringkasan Sentimen Esktraktif di Twitter Menggunakan Hybrid TF-IDF dan Cosine Similarity. IJCCS (Indonesian Journal of Computing and Cybernetics Systems), 10(2), 207-218. 


\section{LAMPIRAN}

\section{Analisis Sentimen}

ja1anto1

$\begin{array}{lrr} & \text { word } & \text { freq } \\ \text { tol } & \text { tol } & 8231 \\ \text { jalan } & \text { jalan } & 7684 \\ \text { mudik } & \text { mudik } & 1166 \\ \text { macet } & \text { macet } & 901 \\ \text { lancar } & \text { lancar } & 845 \\ \text { status } & \text { status } & 492 \\ \text { arah } & \text { arah } & 484 \\ \text { jam } & \text { jam } & 452 \\ \text { arus } & \text { arus } & 423 \\ \text { lebaran } & \text { lebaran } & 403 \\ \text { jokowi } & \text { jokowi } & 398 \\ \text { mobi1 } & \text { mobi1 } & 395 \\ \text { jakarta } & \text { jakarta } & 394 \\ \text { maha1 } & \text { maha1 } & 394 \\ \text { jawa } & \text { jawa } & 376 \\ \text { bayar } & \text { bayar } & 358 \\ \text { orang } & \text { orang } & 354 \\ \text { jalur } & \text { jalur } & 336 \\ \text { trans } & \text { trans } & 321 \\ \text { masuk } & \text { masuk } & 302 \\ & & \end{array}$

$>$ posneg <- table(Resu1t2\$1abe1)

$>$ posneg

negative netral positive $4814 \quad 823 \quad 425$

$>$ prop.table(posneg)

negative netral positive $\begin{array}{lllll}0.79412735 & 0.13576377 & 0.07010887\end{array}$

\section{Bandara}

word freq

Tebaran

pesawat

penumpang

soekarno

hatta

mudik

terminal

tiket

jam

arus

sepi

internasional internasionat 250

status status 236

udah udah 234

soetta soetta 228

pemudik pemudik 220

petugas petugas 215

jalan

orang

indonesia

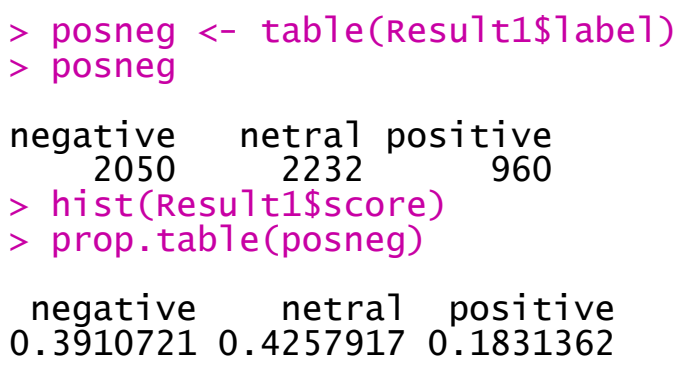

Naïve Bayes

Bandara

Confusion Matrix and Statistics

Reference

Prediction negative positive negative $\quad 339 \quad 76$ $\begin{array}{lll}\text { positive } & 14 & 71\end{array}$

Accuracy : 0.82 


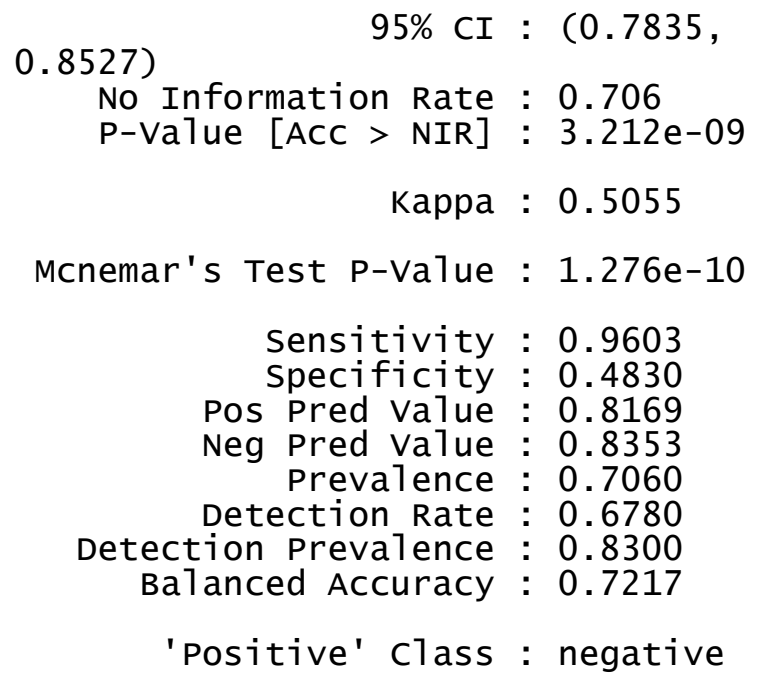

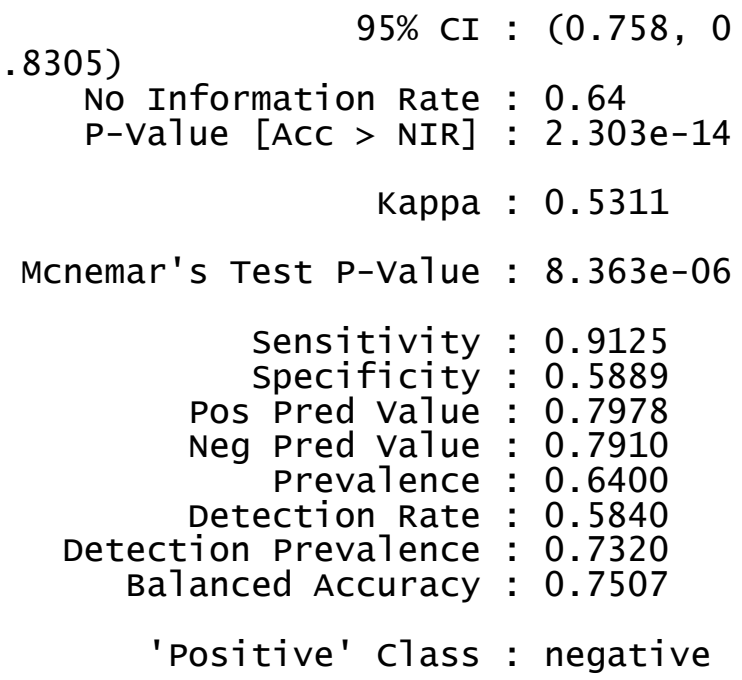

\section{MRT}

Confusion Matrix and statistics

\begin{tabular}{crc}
\multicolumn{3}{c}{ Reference } \\
Prediction & negative & positive \\
negative & 292 & 74 \\
positive & 28 & 106 \\
& Accuracy & $: 0.796$
\end{tabular}

